\title{
Cleavage and Inactivation of Factor IX by
}

\section{Granulocyte Elastase}

\author{
Akira Takaki, David L. Enfield, and Arthur R. Thompson, Department of \\ Medicine, University of Washington and Seattle Public Health Hospital and \\ the Puget Sound Blood Center, Seattle, Washington 98144
}

A B S T R A C T Radioiodinated Factor IX was cleaved by a crude sonicate from leukocytes. In the absence of calcium, fragments of $<15,000 \mathrm{~mol}$ wt were seen from reduced samples on gel electrophoresis. After digestion in $2 \mathrm{mM}$ calcium, however, electrophoresis of reduced samples showed, in addition to low molecular weight fragments, protein bands corresponding in size to heavy and light chains of Factor XIa-activated Factor IX. The cleaving activity in leukocyte sonicates was inhibited by soybean trypsin inhibitor, but only to a small extent by aprotinin.

Granulocyte elastase was isolated from purified polymorphonuclear leukocyte granules by affinity chromatography on soybean trypsin inhibitor-agarose and further chromatography on carboxymethyl cellulose. The purified fraction contained two isozymes on acidic gels which cleaved both an ester sensitive to elastase and radiolabeled Factor IX. These two activities were inhibited by elastase-specific chloromethyl ketone. The isolated protease fraction rapidly inactivated apparent Factor IX activity in a coagulant assay system. The degree of inactivation correlated with the amount of intact, radiolabeled Factor IX cleaved. As with the crude sonicate, generation of the larger heavy and light chain-sized fragments was dependent upon calcium.

To assess directly the effect of elastase on Factor IX, an immunospecific, active site-directed assay was developed. In this assay, the sample was incubated with solid-phase antibody to Factor IX and the amount of activated product was detected as that which had complexed with radioiodinated antithrombin III. In this

Dr. Takaki's present address is the University of Occupational and Environmental Health, School of Medicine, Yahata Nishi Ku, Kitakyushu 807 Japan. Address correspondence to Dr. Thompson.

Received for publication 3 January 1983 and in revised form 10 June 1983. system, exposure of Factor IX to Factor XIa showed progressive increase in the ability to bind antithrombin III, whereas after elastase, Factor XIa was unable to generate antithrombin III binding. The elastase-degraded Factor IX did not inhibit activation of additional Factor IX in clotting assays. When Factor IXa was incubated with elastase, binding of antithrombin III was decreased, corresponding to appearance of low molecular weight fragments on parallel samples that were reduced and electrophoresed. These data are consistent with elastase inactivating Factor IX by cleaving bonds near, but distinct from, bonds cleaved by Factor XIa.

\section{INTRODUCTION}

It is well established that Factor XIa activates Factor IX by two activation cleavages (1). However, no plasma cofactor or means of achieving a sufficient local concentration of these trace plasma proteins has been identified. Under some conditions, it has also been shown that Factor VIIa with tissue factor cleaves Factor IX (2), but the significance of this proteolysis has not been well established. Even less is known about the susceptibility of Factor IX or IXa to degradative cleavages, although partial degradation would serve as a potent means of limiting the coagulation response at an early stage.

In contrast to a system of proteolysis composed of interactions between plasma proteins, physiologic or pathologic cleavage of Factor IX could occur by cellular neutral proteases. This possibility was suggested by data of Kingdon et al. (3) who noted generation of a Factor IXa-like procoagulant activity when a crude concentrate containing Factor IX was incubated with a granulocyte sonicate. The degree of activation, however, could not be assessed by their clotting assays which would have been sensitive to modification of Factor VIII or other effects upon their generated Factor IXa-like activity. Furthermore, their activity re- 
quired a plasma protein fraction as a cofactor, conceivably to prevent inactivation of Factor IX.

Probably the major neutral protease from granulocytes is an elastase. In patients with disseminated intravascular coagulation, high levels of granulocyte elastase were detected in plasma, complexed to $\alpha_{1}$-antitrypsin (4). Indeed, this elastase is released during in vitro clotting of whole blood or even recalcified plasma enriched with isolated neutrophils (5). Elastase would thus be available to cleave clotting factors, at least at local sites of inflammation, before its inactivation.

In approaching the problem of Factor IX proteolysis by granulocytic enzymes, we initially found that crude granulocyte preparations would cleave ${ }^{125}$ I-Factor IX to yield either low molecular weight peptides or, in the presence of calcium, heavy chain and light chainsized fragments, suggestive of activation. ${ }^{1}$ As an extension of this preliminary observation, we have now examined the effect of granulocyte elastase on Factor IX in an isolated system. Electrophoresis of reduced ${ }^{125}$ I-Factor IX samples was used as an index of cleavage. Because there has been no specific functional assay for Factor IXa, an immunospecific, radiolabeled-inhibitor assay was developed to test for generation of the Factor IX active site.

\section{METHODS}

Materials. Chemicals were purchased from the following sources: Coomassie Brilliant Blue (R-250), Methyl Green, acrylamide, $N, N^{\prime}$ methylenebisacrylamide, $N, N, N^{\prime} N^{\prime}$-tetramethyl-ethylene diamine, sodium dodecyl sulfate, ammonium persulfate, carboxymethyl $(\mathrm{Cm})^{2}$ cellulose (Cellex-CM), and lactoperoxidase-glucose oxidase reagent (Enzymobead) from Bio-Rad Laboratories, Richmond, CA; Sepharose 4B and Sephadex G-25 and G-75 from Pharmacia Fine Chemicals, Piscataway, NJ; Ficoll (Histopaque-1077), dextran (industrial grade, 161,000 average mol wt), trypsin inhibitor (type I-S from soybean), $N \alpha$ - $p$-toluenesulfonyl (Tos)-L-Lys chloromethyl ketone, L-1-tosylamide-2-phenyl-ethyl chloromethyl ketone, $N$-benzoyl $(\mathrm{Bz})$-L-Tyr ethyl ester, $N$-benzyloxycarbonyl (Cbz)-L-Lys-p-nitrophenyl ester, $N$-tert-butoxycarbonyl (t-BOC)-L-Ala-p-nitrophenyl ester, heparin, bovine albumin (fraction $\mathrm{V}$ ), rabbit brain cephalin, porcine pancreatic elastase (type I), $\alpha_{1}$-antitrypsin, and dithiothreitol, Sigma Chemical Co., St. Louis, MO; $\left[{ }^{125} \mathrm{I}\right]$ sodium iodide $(2 \mathrm{mCi} / 20$ $\mu \mathrm{l})$, New England Nuclear, Boston, MA. Factor IX was isolated from plasma and radioiodinated as previously described (6) and the following were generous gifts from sources as in-

\footnotetext{
${ }^{1}$ A preliminary investigation on the effects of granulocyte sonicates and granule fractions has been presented (Thompson, A. R., A. Takaki, D. L. Enfield, and D. G. Wright. 1980. Clin. Res. 28:326A).

${ }^{2}$ Abbreviations used in this paper: $\mathrm{Bz}$, benzoyl; $\mathrm{Cbz}$, benzyloxycarbonyl; Cm, carboxymethyl; MeO, methoxy; Suc, succinyl; t-BOC-, tertbutoxycarbonyl; Tos, p-toluenesulfonyl.
}

dicated: methoxy (MeO)-succinyl(Suc)-Ala-Ala-Pro-Val chloromethyl ketone (7), Dr. James C. Powers, Georgia Institute of Technology, Atlanta, GA; human Factor XIa (8) and human antithrombin III-heparin complex (9), Dr. Kotoku Kurachi, and affinity-purified goat anti-human Factor IX, ${ }^{3}$ Dr. Walter Kisiel, both of the Department of Biochemistry, University of Washington. Tris-buffered saline was composed of $0.1 \mathrm{M} \mathrm{NaCl}$ in $50 \mathrm{mM}$ Tris- $\mathrm{HCl}, \mathrm{pH} 7.5$ (unless otherwise indicated).

Preparation of granule extracts. The preparation of granule extracts was adapted from the method of West et al. (11). Granulocyte-rich fractions were isolated from buffycoat layers prepared from whole blood of consenting, normal donors and purchased from the Puget Sound Blood Center. The preparations contained citrate-phosphate-dextrose with adenine. Buffy-coat layers from four units of whole blood were pooled, yielding an average of $240 \mathrm{ml}$ of packed cells; heparin $(20 \mathrm{U} / \mathrm{ml})$ was then added, followed by $200 \mathrm{ml}$ of $0.15 \mathrm{M} \mathrm{NaCl}$. Within $6 \mathrm{~h}$ after being drawn, cells were sedimented in $1 / 2$ vol of Ficoll reagent under a centrifugal force of $400 \mathrm{~g}$ for $30 \mathrm{~min}$. After discarding the supernatant layers, a volume of $3 \%$ dextran twice that of the starting cell fraction was aliquoted in equal volumes into the centrifuge tubes and mixed; the erythrocytes were then allowed to sediment at room temperature for $30 \mathrm{~min}$. By centrifuging at $400 \mathrm{~g}$ for $10 \mathrm{~min}$, leukocytes with some erythrocyte contamination were collected from the supernate. Hypotonic lysis of the remaining erythrocytes was accomplished in three cycles of alternatively washing with equal volumes of 0.2 and $1.6 \%$ $\mathrm{NaCl}$. From the final centrifuged precipitate, the granulocytes were resuspended in $20 \mathrm{ml} 0.34 \mathrm{M}$ sucrose with 10,000 $U$ heparin and lysed by aspiration and expression 18 times through a 20-gauge needle. Cellular debris was removed by centrifugation at $1,000 \mathrm{~g}$ for $10 \mathrm{~min}$. The granule fraction was obtained as a pellet from a second centrifugation at $28,000 \mathrm{~g}$ for $30 \mathrm{~min}$; the pellets were resuspended in $4 \mathrm{ml}$ Tris-buffered saline and stored at $-80^{\circ} \mathrm{C}$. Three preparations from $4 \mathrm{U}$ of granulocyte-rich fraction were combined and sonicated in a Bransonic- 12 water bath for $3 \mathrm{~min}$ and then centrifuged at $40,000 \mathrm{~g}$ for $30 \mathrm{~min}$. The pellets were resuspended in $30 \mathrm{ml}$ Tris-buffered saline and frozen and thawed five times to ensure granule membrane lysis. Granule supernatants obtained subsequent to freezing, thawing, and centrifugation $(40,000 \mathrm{~g}$ for $30 \mathrm{~min})$ were combined and dialyzed against Tris-buffered saline.

Isolation of elastase isozymes. Affinity and ion-exchange chromatography were performed similarly to the method of Baugh and Travis (12), except soybean trypsin inhibitor was used as the affinity ligand instead of aprotinin. Soybean trypsin inhibitor-agarose was prepared by $\mathrm{CNBr}$ activation (6) of $50 \mathrm{ml}$ Sepharose $4 \mathrm{~B}$, followed by stirring overnight with $1 \mathrm{~g}$ soybean trypsin inhibitor at $4^{\circ} \mathrm{C}$. Columns $(2.5 \times 4 \mathrm{~cm})$ of resin were equilibrated with Tris-buffered saline and the sample of lysed granules from $12 \mathrm{U}$ of buffy coat applied. The column was consecutively washed with $100 \mathrm{ml}$ each of Tris-buffered saline and $0.5 \mathrm{M} \mathrm{NaCl}$ in $50 \mathrm{mM}$ Tris (pH 7.5). Crude elastase was eluted with $50 \mathrm{ml} 0.1 \mathrm{M}$ acetic acid. After dialysis against $0.15 \mathrm{M} \mathrm{NaCl}$ in $10 \mathrm{mM}$ sodium acetate $(\mathrm{pH}$ 5.6), the crude preparation was applied to a $\mathrm{Cm}$-cellulose column $(1 \times 20 \mathrm{~cm})$ equilibrated with the same buffer. After a 150-ml wash with start buffer (to an $A_{280}$ below 0.01), a

\footnotetext{
${ }^{3}$ Purified by Dr. Kisiel as described for alloantibodies (10), the preparation migrated as homogenous IgG on polyacrylamide gels in sodium dodecyl sulfate.
} 
linear gradient consisting of $250 \mathrm{ml}$ each of $0.15 \mathrm{M}$ and 0.3 $\mathrm{M} \mathrm{NaCl}$, both in $10 \mathrm{mM}$ sodium acetate, pH 5.6, was run. Compared with other preparations (12), a lower $\mathrm{NaCl}$ concentration was used in the final buffer to minimize potential contamination. Final $\mathrm{Cm}$-cellulose fractions were concentrated by chromatography on soybean trypsin inhibitor-agarose columns with elution in $0.1 \mathrm{M}$ acetic acid followed by dialysis against Tris-buffered saline. Purity was assessed by disc-gel electrophoresis at $\mathrm{pH} 4.5$ (13) on $15 \%$ polyacrylamide gels containing $0.1 \%$ sodium dodecyl sulfate.

Factor IX cleaving activity. Cleavage of Factor IX was carried out in dilute solutions containing $2 \mu \mathrm{g}$ unlabeled Factor IX and to $20,000 \mathrm{cpm}{ }^{125} \mathrm{I}-$ Factor IX in $100-\mu \mathrm{l}$ final volumes. Factor XIa or elastase was added in Tris-buffered saline at $37^{\circ} \mathrm{C}$. Typically, enzyme to substrate ratios were 1:75 and 1:10, respectively; $\mathrm{CaCl}_{2}$ was added to a final concentration of 2-6 mM. Reactions were stopped by either sodium dodecyl sulfate with or without dithiothreitol (14), antithrombin III with heparin, or $\alpha_{1}$-antitrypsin. Samples with sodium dodecyl sulfate were incubated overnight at $37^{\circ} \mathrm{C}$, and run on $10 \%$ polyacrylamide gels containing $0.1 \%$ sodium dodecyl sulfate (15). Gels were sliced in an electric gel slicer (2.0 mm; Bio-Rad Laboratories model 195) and slices counted in a Nuclear Chicago Gamma Counter (Chicago, IL; model 1085, $80 \%$ efficient). For some experiments, 2.5-mm slices were prepared by hand.

Factor IXa-antithrombin III binding assay. Labeling of antithrombin III with lactoperoxidase-glucose oxidase reagent was carried out according to the manufacturer's instructions. Typically, $25 \mu \mathrm{g}$ human antithrombin III (1 mg/ ml) complexed with heparin (9) was labeled with $1 \mathrm{mCi}$ $\left[{ }^{125} \mathrm{I}\right]$ sodium iodide at ambient temperature for 10-20 min. The mixture was desalted on a $10-\mathrm{ml}$ column of Sephadex G-25 (medium) that had been prewashed with $2 \mathrm{ml}$ of $10 \%$ bovine albumin in Tris-buffered saline and rinsed with 10 $\mathrm{ml}$ of the same buffer without the albumin. The reaction mixture was applied to this column and was then eluted with Tris-buffered saline.

For the assay, purified goat anti-Factor IX, which contained $19 \mathrm{mg} / \mathrm{ml}$ protein and 800 Bethesda inhibitor $\mathrm{U} / \mathrm{ml}$, was diluted 1:500 in 0.1 $\mathrm{M} \mathrm{NaHCO}_{3}(\mathrm{pH} \mathrm{9.5)}$ and $100 \mu \mathrm{l}$ was incubated for $1 \mathrm{~h}$ at $37^{\circ} \mathrm{C}$ in microtiter wells (Imulon-I Removawell Strips, Dynatech Laboratories, Inc., Alexandria, VA). After incubation, wells were washed three times with Tris-buffered saline containing $0.1 \%$ albumin. Unlabeled Factor IX was incubated with enzymes as indicated above in the cleaving assay; reactions were terminated by diluting an aliquot into an excess of ${ }^{125} \mathrm{I}$-antithrombin III with heparin. The Factors IX and/or IXa-antithrombin III mixtures were then diluted to $120 \mu \mathrm{l}$ with $0.1 \%$ albumin in Tris-buffered saline, and $100 \mu \mathrm{l}$ transferred to the antibody-coated wells; incubations were 2-6 h at room temperature. After this incubation, wells were washed three times with Trisbuffered saline containing $0.1 \%$ albumin and counted. Percentage binding was determined from precounting of the wells before washing. For some assays, EDTA or $\alpha_{1}$-antitrypsin were added.

Enzyme assays. Elastase activity was determined by the spectrophotometric method of Visser and Blout (16) using $N$-t-BOC-L-Ala- $p$-nitrophenyl ester as the substrate; the procedure was performed in phosphate buffer at $\mathrm{pH} 6.5$ and $30^{\circ} \mathrm{C}$, using a Gilford spectrophotometer with auto cuvette positioner and recorder (models 252, 2451-A, and 6051, respectively, Gilford Instrument Laboratories, Inc., Oberlin, $\mathrm{OH})$. One unit of activity was arbitrarily defined as the release of $1 \mu \mathrm{mol} p$-nitrophenol $\mathrm{min}^{-1} \mathrm{ml}^{-1}$ and activity was recorded as $\Delta A_{347.5} \mathrm{~min}^{-1}$. Under these conditions, a $1 \%$ change in elastase concentration was detectable. The hydrolysis of $N$ $\mathrm{Bz}-\mathrm{L}-\mathrm{Ty} \mathrm{r}$ ethyl ester was determined by the method of Hummel (17) and, the $N$-Cbz-L-Lys- $p$-nitrophenyl ester by the method of Silverstein (18). Protein concentrations were calculated from $A_{280}$ with $E_{1 \mathrm{~cm}}^{1 \%}$ values of 9.85 and 13.3 for elastase (12) and Factor IX (19), respectively. For routine inhibitor studies, granulocyte enzyme fractions were incubated with a final concentration of $1 \mathrm{mM} \mathrm{L-1-tosylamide-2-phenylethyl}$ chloromethyl ketone, Tos-L-Lys chloromethyl ketone, or MeO-Suc-Ala-Ala-Pro-Val chloromethyl ketone at $4^{\circ} \mathrm{C}$ for $18 \mathrm{~h}$ before dilution for esterolytic assays or determination of ${ }^{125} \mathrm{I}-\mathrm{Factor}$ IX digesting activity.

Factor IX clotting activity and inhibition were determined by the one-stage partial thromboplastin time with kaolin and deficient plasma as previously described (6). For Factor IXa coagulant activity, kaolin was omitted and substrate plasma, phospholipid, and sample were warmed for $15 \mathrm{~s}$ at $37^{\circ} \mathrm{C}$ before recalcification; tipping in siliconized glass tubes and reagents were as otherwise described for the assay with contact activation (6). In testing for inhibition of Factor IX coagulant activity, elastase-degraded Factor IX was added to normal and Factor IX-deficient plasmas before the kaolin activated, one-stage assay.

\section{RESULTS}

After the separation of leukocytes and hypotonic lysis of erythrocytes, granulocytes represented $96 \%$ of the white cells on the basis of differential cell counts. In preliminary experiments, granule extracts were found to digest ${ }^{125}$ I-Factor IX into peptides and fragments of mol wt $<15,000$. However, when cleavage was performed in the presence of $2 \mathrm{mM}$ calcium, and the reduced samples electrophoresed, half of the radioactivity appeared in bands of higher molecular weight. These corresponded in size to the heavy and light chains of Factor XIa-activated Factor IX (see Fig. 1). For subsequent studies, $\mathrm{CaCl}_{2}$ was included in digests of ${ }^{125} \mathrm{I}$-Factor IX. Additionally, upon incubation of Factor IX with the crude granule preparations in the presence of aprotinin, only $10 \%$ of ${ }^{125}$ I-Factor IX remained uncleaved as compared with $65 \%$ or more when comparable amounts of soybean trypsin inhibitor were added (Fig. 2). This effect of soybean trypsin inhibitor provided the rationale for its use in the purification scheme.

Purification and characterization of human granulocyte elastase. Upon fractionating the crude granule lysate preparation on soybean trypsin inhibitor-agarose, one-third of the applied protein was found each in the breakthrough peak, the $\mathrm{NaCl}$ wash, and the acetic acid eluate. Factor IX degrading activity was confined to the acid eluate as was hydrolyzing activity against $N$ t-BOC-L-Ala- $p$-nitrophenyl ester, the elastase substrate. This eluate fraction failed to cleave the tyrosyl or lysyl esters tested (see Methods). During Cm-cellulose chromatography at $4^{\circ} \mathrm{C}$, the majority of the protein did not bind and eluted before the start of the linear gradient. 


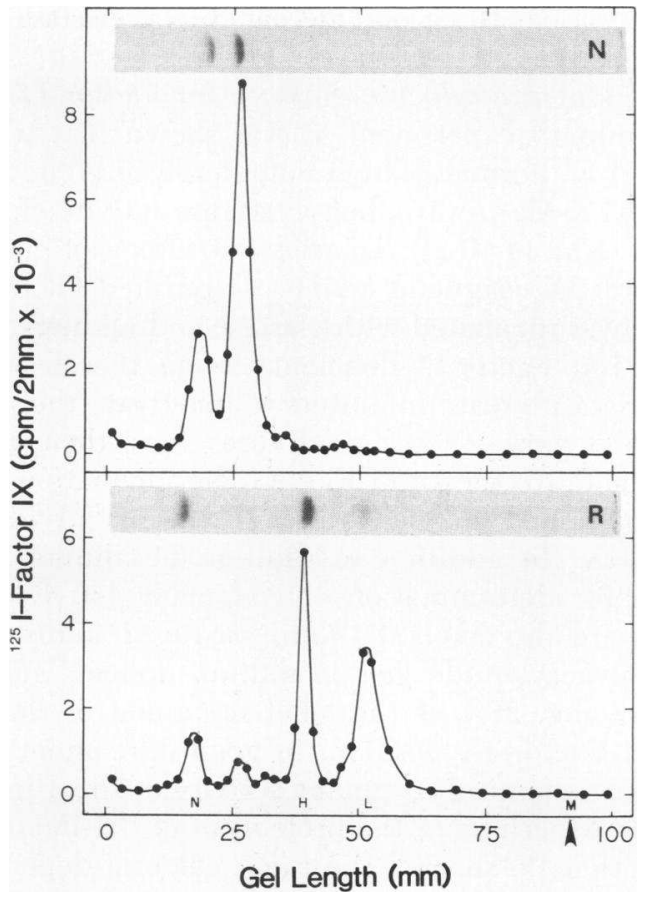

Figure 1 Cleavage of Factor IX by Factor XIa. Factor IX $(25 \mu \mathrm{g})$, containing a trace of ${ }^{125} \mathrm{I}-\mathrm{F}$ actor IX, was incubated at $37^{\circ} \mathrm{C}$ for $1 \mathrm{~h}$ with $0.5 \mu \mathrm{g}$ Factor XIa in Tris-buffered saline containing $2 \mathrm{mM}$ calcium chloride. The samples were then electrophoresed on $10 \%$ polyacrylamide in the presence of $0.1 \%$ sodium dodecyl sulfate; the anode is to the right. Upper panel shows a stained gel $(N)$ of a nonreduced sample above a profile of the corresponding counts from gel slices, indicating $75 \%$ cleavage. Lower panel shows a stained gel $(R)$ of a reduced sample and corresponding counts from the slices. For reference, letters indicate migration distances of nondigested Factor IX $(N)$, heavy $(H)$, and light $(L)$ chains and the dye marker ( $M$, arrow). On more heavily loaded gels (not shown), with protein or carbohydrate staining, the activation peptide was visualized as a broad, lightly staining band between 70 and $80 \mathrm{~mm}$; it did not radioiodinate.

Three smaller peaks were demonstrated by absorbance at $280 \mathrm{~nm}$ during gradient elution of four separate preparations. All four $\mathrm{Cm}$-cellulose fractions (the breakthrough and three elution peaks, subsequently referred to as fractions I-IV, respectively) contained Factor IX digesting and elastase-like esterase activity. Fraction I was further purified on G-75 Sephadex where elastase and Factor IX cleaving activities were confined to the void volume; lower molecular weight proteins and peptides were inactive in both assays. Fraction IV showed two distinct bands (Fig. 3) upon disc-gel electrophoresis at $\mathrm{pH}$ 4.3. Nonfixed gels, which had been run at the acidic $\mathrm{pH}$, were sliced and eluted into Trisbuffered saline $(0.2 \mathrm{ml}$ for each $1-\mathrm{mm}$ slice); each of the two peaks contained elastase-like esterase (Fig. 3) and ${ }^{125} \mathrm{I}$-Factor IX-cleaving activities. On gel electro- phoresis, fraction I contained a single broad band from 10 to $13 \mathrm{~mm}$ migration, fraction II had a doublet of bands at 12 and $13 \mathrm{~mm}$, and fraction III yielded a banding pattern with features of both fractions II and IV (not shown).

The elastase fractions were further characterized by their interactions with chloromethyl ketones. Using the sensitive $\boldsymbol{N}$-t-BOC-L-Ala- $p$-nitrophenyl ester assay for elastase activity, 27 and $25 \%$ inhibition of the activity of fractions I and II, respectively, were obtained with the chymotrypsin inhibitor, tosyl-amide-2-phenylethyl chloromethyl ketone, whereas the trypsin inhibitor, $\mathrm{N} \alpha$-Tos-L-Lys-chloromethyl ketone, inhibited only fraction I, reducing its activity by $18 \%$. These two inhibitors had no effect upon the esterase activity of fraction IV. However, with MeO-Suc-Ala-Ala-Pro-Val chloromethyl ketone, the specific inhibitor of elastase (7), 73-75\% inhibition of the initial esterase activity of all fractions was obtained. These results suggest that $\mathrm{Cm}$-cellulose fractions I and II were contaminated with traces of a chymotrypsin-like enzyme and that fraction I also contained a trypsin-like enzyme. Attempts to isolate the latter by chromatography on lysyl-agarose were unsuccessful. The effects of these inhibitors on cleavage of Factor IX by the elastase fractions are shown in Table I. Inhibition of the esterase of fraction IV by MeO-Suc-Ala-Ala-Pro-Val chloromethyl ketone was studied further. Isozymes eluted from gels (see Fig. 3), and a separate incubation (1.5 $\mu$ g elastase in $100 \mu \mathrm{l})$ were $>99 \%$ inhibited after $2-\mathrm{h}$ incubations at $37^{\circ} \mathrm{C}$ with a $1 \mathrm{mM}$ final concentration of the specific inhibitor.

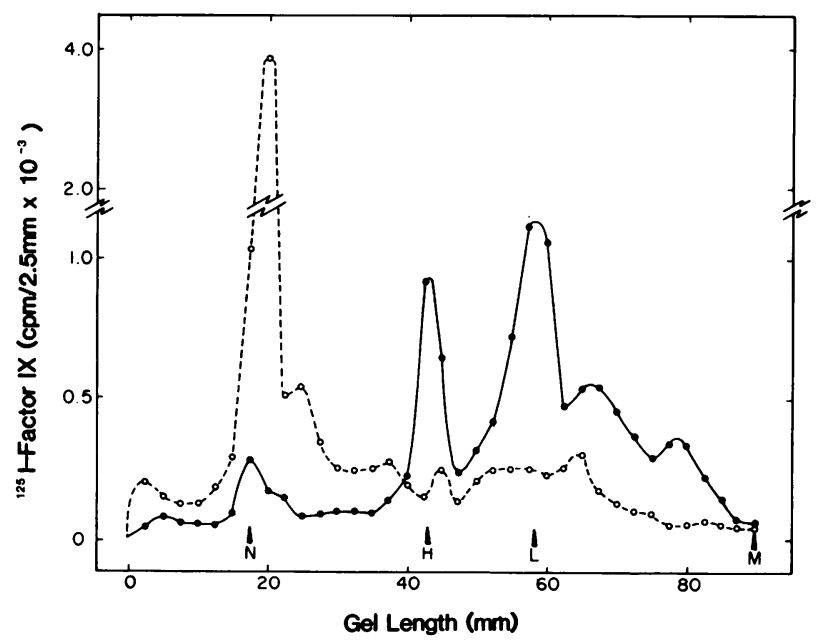

FIGURE 2 Digestion of ${ }^{125}$ I-Factor IX by a crude granulocyte sonicate. Incubation and electrophoresis were performed as in Fig. 1, except that the samples were digested with granule sonicate, in the presence $(O)$ or absence $(O)$ of soybean trypsin inhibitor. The samples were reduced before electrophoresis. 


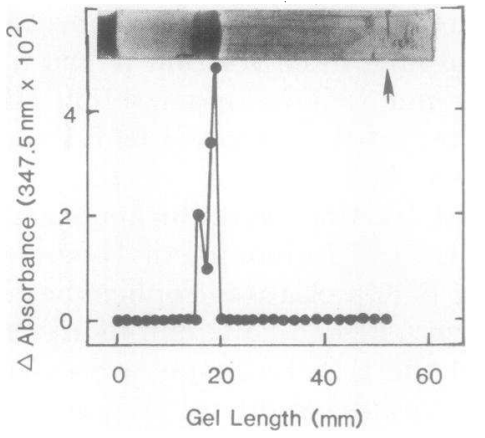

Figure 3 Granulocyte elastase fraction IV. Electrophoresis was on $15 \%$ polyacrylamide disc gels in sodium dodecyl sulfate at $\mathrm{pH}$ 4.3. The two bands on the gel (top) correspond to the location of esterase activity as determined on a gel run in parallel, then sliced, eluted in Tris-buffered saline, and assayed. Hydrolysis of $N$-t-BOC-L-Ala- $p$-nitrophenyl ester was recorded as the change in absorbance at $347.5 \mathrm{~nm} / \mathrm{min}$ compared with a nonenzyme control. Two additional preparations of $\mathrm{Cm}$-cellulose fraction IV were tested and gave the same results. The arrow indicates the position of the marker dye.

Cm-cellulose fraction IV, containing two elastase isozymes, was used for subsequent studies. In the esterase assay, 1:35 $\mu \mathrm{g}$ fraction IV had 1.38 arbitrary units in the $N$-t-BOC-L-Ala- $p$-nitrophenyl ester assay.
In comparison, $10 \mu \mathrm{g}$ porcine pancreatic elastase contained $0.98 \mathrm{u}$.

Effects of granulocyte elastase on Factor IX. In a preliminary experiment, it was shown that within $1 \mathrm{~min}, 1 \mu \mathrm{l}$ normal plasma completely inhibited the $N$-t-BOC-L-Ala- $p$-nitrophenyl esterase activity of fraction IV $(1 \mu \mathrm{g}$ in $10 \mu \mathrm{l})$. To assess the effects of elastase on Factor IX coagulant activity, a purified Factor IX sample was incubated with elastase and aliquots were diluted into Factor IX-deficient plasma, thereby using the plasma protease inhibitors to inactivate the granulocyte enzyme. Clotting activities were then determined and are shown in Fig. 4. The incubation mixtures contained unlabeled and a trace of ${ }^{125}$ I-labeled Factor IX. In addition to dilution of aliquots into plasma for determination of coagulant activity, aliquots were also taken at $10 \mathrm{~min}$, reduced, and run on $10 \%$ polyacrylamide gels in sodium dodecyl sulfate. After slicing, $28 \%$ of the label remained in the uncleaved Factor IX position, in good agreement with the $25 \%$ remaining coagulant activity at this time. In separate experiments, the proteolysis of ${ }^{125} \mathrm{I}$-Factor IX by fraction IV showed the same calcium-dependent specific cleavages (Fig. 5) as previously found when the crude granulocyte preparation was used. As before, in the absence of calcium, only fragments of $<15,000$ mol wt were obtained.

TABLE I

Effects of Chloromethyl Ketone Inhibitors on Factor IX Cleavage by Elastase Fractions

\begin{tabular}{|c|c|c|c|c|c|c|c|c|}
\hline \multirow[b]{2}{*}{ Factor IX peak $(\mathrm{mm})^{\bullet}$} & \multicolumn{2}{|c|}{ Fraction I } & \multicolumn{2}{|c|}{ Fraction II } & \multicolumn{4}{|c|}{ Fraction IV } \\
\hline & None & E-CMK & None & E-CMK & None & E-CMK & TPCK & TLCK \\
\hline Uncleaved (17-20) & 24 & 51 & 15 & 91 & 14 & 63 & 14 & 15 \\
\hline Intermediate $(21-26)$ & 21 & 21 & 20 & 7 & 5 & 21 & 5 & 3 \\
\hline Heavy chain $(33-38)$ & 8 & 4 & 11 & 0 & 15 & 5 & 13 & 15 \\
\hline Light chain $(43-50)$ & 34 & 19 & 38 & 2 & 33 & 9 & 41 & 39 \\
\hline Fragments $(>51)$ & 13 & 5 & 16 & 0 & 33 & 2 & 27 & 28 \\
\hline
\end{tabular}

Elastase fractions were incubated $24 \mathrm{~h}$ at $4^{\circ} \mathrm{C}$ in $1 \mathrm{mM}$ inhibitor and then diluted 75150 -fold in a final cleavage mixture that contained $2 \mu \mathrm{g}$ Factor IX with trace ${ }^{125} \mathrm{I}$-Factor IX and was incubated $30 \mathrm{~min}$ at $37^{\circ} \mathrm{C}$ in Tris-buffered saline with $5 \mathrm{mM} \mathrm{CaCl}_{2}$ (final volume $50 \mu \mathrm{l}$ ). Cleavage is expressed as percent counts per minute in each peak for reduced samples on $10 \%$ polyacrylamide gels electrophoresed in sodium dodecyl sulfate (see Fig. 1 legend). From 70 to $85 \%$ of the $3-5,000 \mathrm{cpm}$ applied were recovered and an average of $95 \%$ of these were present in the slices indicated; percents in vertical columns were adjusted to $100 \%$ of counts present in the indicated peaks.

Abbreviations used in this table: E-CMK, MeO-Suc-Ala-Ala-Pro-Val chloromethyl ketone; TPCK, L-1-tosylamide-2-phenylethyl chloromethyl ketone; and TLCK, Na-TosL-Lys chloromethyl ketone.

- Peaks typically migrated within the millimeters of gel specified when the marker dye front migrated $80 \mathrm{~mm}$ toward the cathode (total gel lengths were near $100 \mathrm{~mm}$ ). Fragments, however, varied from representing two distinct peaks to a single, broad zone of radioactivity beyond the light chain peak. 


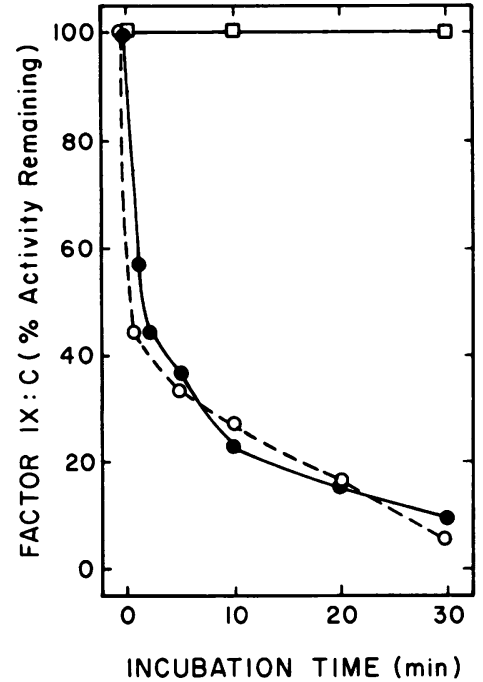

FIgURE 4 Inactivation of Factor IX coagulant activity by elastase. Factor IX was incubated with $\mathrm{Cm}$-cellulose fraction IV in 1:5 (O) or 1:10 (O) elastase to Factor IX ratios. At timed intervals, twenty-fold dilutions into Tris-buffered saline were made and the Factor IX clotting activity of a 0.1$\mathrm{ml}$ aliquot determined. Activity was compared with a standard curve determined with normal pooled plasma; the control ( $\square$ ) represents Factor IX without elastase; elastase alone at this dilution had no effect on a partial thromboplastin time of normal plasma (not shown).

To explore whether a Factor IXa species was formed either partially or transiently during cleavage by fraction IV, an immunospecific, labeled-inhibitor assay was used. It had been shown that $(a)$ Factor IX itself would not bind ${ }^{125} \mathrm{I}$-antithrombin III; $(b)$ during incubation with Factor IXa, a time-dependent increase of binding of the labeled inhibitor was observed; and (c) at its lower limit, the assay could detect as little as $2 \mathrm{ng}$ Factor IXa in volume of $0.1 \mathrm{ml}(20,21)$.

In preliminary experiments, elastase incubated with unlabeled Factor IX at an enzyme to substrate ratio of 1:10 showed no binding of ${ }^{125} \mathrm{I}$-antithrombin III. In control experiments with Factor IXa, however, it was noted that elastase itself could interfere with the assay. This interference was not because of effects on the antibody-coated wells, as preincubations of elastase in the wells did not decrease the ability of the antibody to bind ${ }^{125}$ I-Factor IX. Adding a 10-fold excess of $\alpha_{1}$ antitrypsin to elastase-treated Factor IXa before (as opposed to after) incubation with ${ }^{125} \mathrm{I}$-antithrombin III did prevent decrease in binding of the complex to the solid-phase antibody. This same excess $\alpha_{1}$-antitrypsin inhibited $>99 \%$ of the elastase esterase activity after a similar $10-\mathrm{min}$ incubation at $37^{\circ} \mathrm{C}$. In subsequent experiments, $\alpha_{1}$-antitrypsin was added before antithrombin III-heparin unless otherwise indicated.
To control for any effects of $\alpha_{1}$-antitrypsin on elastase cleavage of Factor IX, digestion of ${ }^{125} \mathrm{I}-\mathrm{Factor}$ IX was repeated on inhibited samples as shown in a time course experiment in the left portion of Table II. Incubations without trace-labeled ${ }^{125}$ I-Factor IX were run in parallel and elastase-inhibited, degraded Factor IX mixtures were incubated with ${ }^{125}$ I-antithrombin III. No radioactivity could be detected by the solid-phase anti-Factor IX antibody, as shown in the upper entry in Table III. To exclude the possibility that lack of binding ${ }^{125}$ I-antithrombin III after elastase digestion may have been because of nonspecific inhibition by $\alpha_{1}$-antitrypsin, the binding experiment was repeated substituting the elastase-specific chloromethyl ketone inhibitor (at a concentration of $10 \mathrm{mM}$ for $10 \mathrm{~min}$ ) for the $\alpha_{1}$-antitrypsin. After the addition of ${ }^{125} \mathrm{I}$-antithrombin III, again the binding of radioactivity remained at background levels. Thus, despite the generation of heavy and light chain-like sized peptides (Table II), no binding of ${ }^{125} \mathrm{I}$-antithrombin III occurred.

Factor IXa was studied to compare effects of elastase on the zymogen and its active enzyme. In studying clotting activity (using Factor IX-deficient plasma for substrate and elastate inhibition and no contact phase activators) $2-\mu \mathrm{l}$ aliquots of Factor IXa decreased the clotting times of the final $302 \mu \mathrm{l}$ assay from 67 to 82 $\mathrm{s}$, but clotting remained at that level after both 10 - and 20 -min incubations. For these studies, elastase to Factor IXa ratios were $1: 8$.

The effects of elastase on Factor IXa were further studied by examining patterns of reduced samples of

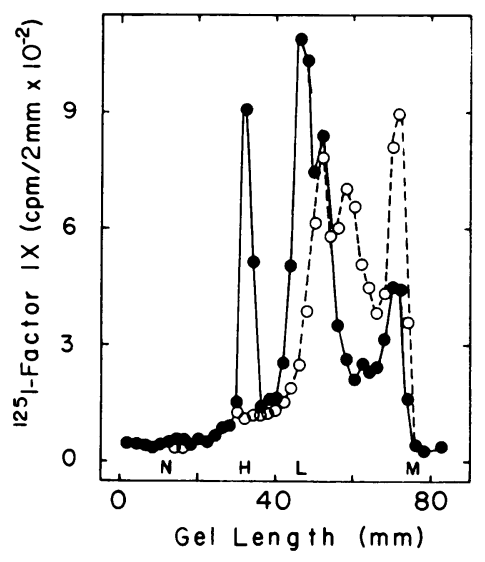

FIgURE 5 Cleavage of ${ }^{125} \mathrm{I}$-Factor IX by elastase. Factor IX ( $1 \mu \mathrm{g}$ ), containing a trace of ${ }^{125} \mathrm{I}-\mathrm{Factor} \mathrm{IX}$, was incubated at $37^{\circ} \mathrm{C}$ for $30 \mathrm{~min}$ with $\mathrm{Cm}$-cellulose fraction IV at a $1: 10$ elastase to Factor IX ratio. Incubation was carried out in Tris-buffered saline, $\mathrm{pH} \mathrm{7.75}$, in the presence $(\Theta)$ or absence (O) of $6 \mathrm{mM}$ calcium chloride. The samples were reduced and electrophoresed and the gels sliced and counted as described for Fig. 1 and in Methods. 
TABLE II

Cleavage of ${ }^{125}$ I-Factor IX and ${ }^{125}$ I-Factor IXa by Elastase; Gel Electrophoresis of Reduced Samples in Sodium Dodecyl Sulfate

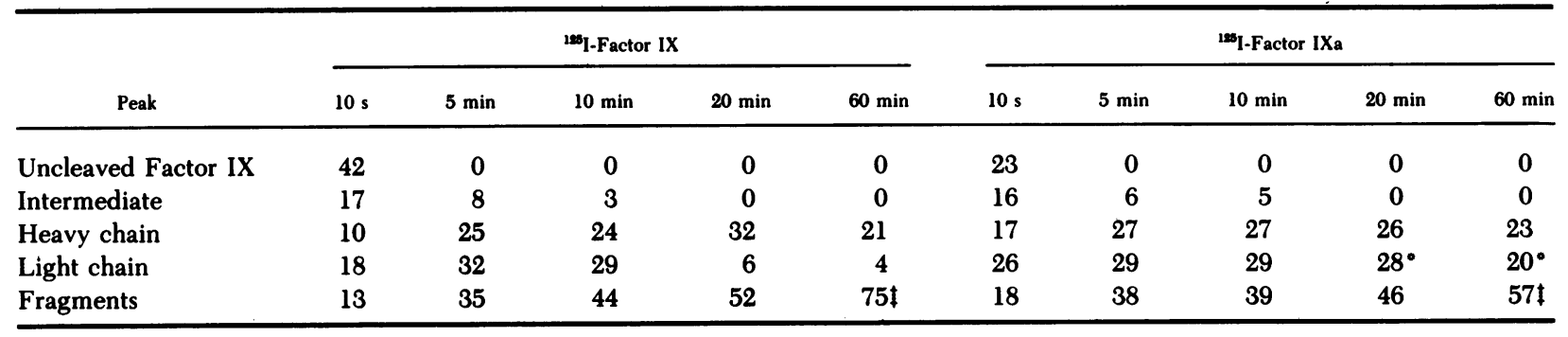

Peak slices (in millimeters), recoveries, and calculations of percent of counts per minute are expressed as described in notes to Table I. For these studies, ${ }^{125}$ I-Factors IX or IXa were incubated with elastase as described in the Methods. At the times given (10 s-60 min), a 10 -fold excess by weight of $\alpha_{1}$-antitrypsin to elastase was added for $10 \mathrm{~min}$ at $37^{\circ} \mathrm{C}$ to inhibit the granulocyte protease. Samples were reduced with dithiothreitol (13) and electrophoresed on $10 \%$ polyacrylamidegels in sodium dodecyl sulfate as described in the text. Parallel, timed incubations (without labeled clotting factor) were taken and incubated with ${ }^{125} \mathrm{I}$-antithrombin III for the immunospecific Factor IXa assay (see Table III).

- Although distinct peaks were observed within these light chain regions, the radioactivity peak was 4 mm (two slices) more anodal than in the previous cleavages indicating a somewhat smaller size.

$\downarrow$ At 60 -min digestion, fragments included $\sim 40$ and $30 \%$ of total counts that migrated beyond the marker dye for Factors IX and IXa, respectively (i.e., counts between 80 and $90 \mathrm{~mm}$ toward the cathode on 100 -mm gels).

${ }^{125}$ I-Factor IXa on gels as shown in the right portion of Table II. For these particular preparations of Factor IX, ${ }^{125} \mathrm{I}$-Factor IX and Factor XIa, approximately onefourth of the ${ }^{125} \mathrm{I}$-Factor IX remained uncleaved after 1-h incubation with Factor XIa, the latter at a 1:60 enzyme to substrate ratio. The time-dependent increase of low molecular weight fragments $(<15,000 \mathrm{~mol} \mathrm{wt}$,

TABLE III

Binding of ${ }^{125}$ I-Antithrombin III to Elastase-degraded Factors IX and IXa

\begin{tabular}{lrrrrr}
\hline & \multicolumn{5}{c}{ Incubation time } \\
\cline { 2 - 6 } Preparation & \multicolumn{1}{c}{$10 \mathrm{~s}$} & \multicolumn{1}{c}{$5 \mathrm{~min}$} & \multicolumn{1}{c}{$10 \mathrm{~min}$} & \multicolumn{1}{c}{$20 \mathrm{~min}$} & \multicolumn{1}{c}{$60 \mathrm{~min}$} \\
\hline Factor IX & $86(0.9)$ & $74(0.8)$ & $65(0.6)$ & $76(0.8)$ & $76(0.8)$ \\
Factor IXa & $790(8.9)$ & $666(7.0)$ & $689(7.7)$ & $635(7.0)$ & $550(5.9)$ \\
\hline
\end{tabular}

Results are expressed as counts per minute bound (over background) and, in parentheses, percent, of the counts bound (vs. precounted wells). Controls with Factor IX before elastase incubation or with albumin instead of the clotting factor ranged from 0.7 to $0.9 \%{ }^{125} \mathrm{I}$ antithrombin III bound. After Factor XIa activation, again without elastase, Factor IXa gave $8.5 \%$ binding on simultaneous controls with the same preparation of labeled inhibitor. An average of $9,550 \mathrm{cpm}$ were added and duplicate determinations ( $n=10$ pairs) varied by an average of $5 \%$ for Factor IXa, and for Factor IX, 9\% of the counts per minute bound.

These experiments were set up in parallel with those in Table II, although the trace label with ${ }^{125}$ I-Factor IX was omitted and (after the 10-min incubation with $\alpha_{1}$-antitrypsin) samples were incubated with ${ }^{125} \mathrm{I}$-antithrombin for $10 \mathrm{~min}$ and then for $2 \mathrm{~h}$ at $23^{\circ} \mathrm{C}$ in anti-Factor IX-coated wells as described in the text. or those migrating further than the light chain) were quite similar to results with ${ }^{125} \mathrm{I}$-Factor IX, including the presence of radioactivity migrating beyond the marker dye after $1 \mathrm{~h}$ of digestion with elastase. As with Factor IX, parallel experiments in which ${ }^{125}$ I-Factor IX was omitted were run for Factor IXa to assess antithrombin III binding. As shown in Table III, there was a gradual decline of the ability to bind antithrombin III that corresponded, at least roughly, to the decrease in Factor IXa clotting activity in separate experiments described above.

Possible inhibitory effects of elastase-degraded Factor IX upon Factor IX procoagulant activity were screened as follows. Factor IX was digested by elastase (as in the left-hand portion of Table II) for $60 \mathrm{~min}$ and dilutions were added to plasmas at levels of $1 / 10(50 \mathrm{ng} /$ $\mathrm{ml})$, equal to $(500 \mathrm{ng} / \mathrm{ml})$, and in 10 -fold excess of $(5$ $\mu \mathrm{g} / \mathrm{ml}$ ) the concentration of Factor IX in the initial 1:10 normal plasma dilution as added to the Factor IX assay. Parallel gels with ${ }^{125}$ I-Factor IX showed complete cleavage of the intact protein. There was no difference in the Factor IX clotting activity in the normal plasma dilution curve with the degraded Factor IX at any of the three concentrations vs. the normal plasma control without added, digested Factor IX. Furthermore, samples from each of the three levels of degraded Factor IX, added to Factor IX-deficient plasma without any normal plasma, gave kaolin clotting times identically prolonged to those of controlled substrate plasmas ( 170 s). These latter results indicate plasma "contact activation product" did not generate Factor IXa coagulant activity from the degraded Factor IX. 
The ability of Factor XIa to generate antithrombin III binding sites from elastase-degraded Factor IX was then assessed. Elastase was preincubated with Factor IX in Tris-buffered saline with $2.5 \mathrm{mM} \mathrm{Ca}^{++}$. After timed incubations at $37^{\circ} \mathrm{C}$, excess $\alpha_{1}$-antitrypsin was added. Factor XIa (1:50 enzyme to substrate ratio) was then added and incubated $30 \mathrm{~min}$ at $37^{\circ} \mathrm{C}$ and the reaction stopped with EDTA ( $5 \mathrm{mM}$ final concentration) and ${ }^{125} \mathrm{I}$-antithrombin III for $10 \mathrm{~min}$ at $37^{\circ} \mathrm{C}$. The mixture was then incubated in the antibody-coated wells for $2 \mathrm{~h}$ at $23^{\circ} \mathrm{C}$ before washing and counting. For the $10-\mathrm{min}$ and 20 -min elastase incubations, 4.1 and $1.7 \%$, respectively, of the excess ${ }^{125}$ I-antithrombin III was bound. These are compared with a $9.9 \%$ value for the simultaneous control without elastase and $0.8 \%$ for the control without Factor XIa. Thus, despite the failure to demonstrate generation of Factor IXa coagulant activity, Factor XIa could form active sites in elastasedegraded Factor IX that were capable of binding antithrombin III-heparin. Furthermore, this effect of Factor XIa was limited by the degree of prior digestion with elastase.

\section{DISCUSSION}

Although cleavage of Factor IX by granulocyte elastase shows generation of fragments of a similar size to those seen with activation by Factor XIa, clotting activity and antithrombin III binding assays indicate that Factor IX is readily inactivated by this cellular neutral protease. The calcium requirement for the more specific Factor IX cleavages is consistent with other data (22, 23) suggesting a calcium-dependent stabilized conformation for Factor IX. As elastase is released from neutrophils during in vitro clotting (5) and since enzymes released on cellular contact have been shown to digest other proteins such as fibronectin (24), it is conceivable that sufficient quantities of elastase could be generated to inactivate Factor IX, or, for that matter, other coagulation proteins, particularly at local sites of inflammation. To test the significance of this reaction, it would be necessary to examine the relative degradation rates of different factors in more complex in vitro systems. In the presence of other protein substrates and enzymes, the cleavage of Factor IX vs. other coagulation factors could be assessed. With these qualifications, it remains plausible that Factor IX degradation by cellular neutral proteases represents a control mechanism for coagulation.

Assessment of activation by using either electrophoretic patterns of cleaved, reduced ${ }^{125}$ I-Factor IX samples (25) or the generation of trichloroacetic acid-soluble ${ }^{3} \mathrm{H}$-carbohydrate activation peptide (26) depends only on physical changes. In dealing with proteases of broader specificity or in more complex reaction mixtures, mere cleavage is not equivalent to activation. As shown with granulocyte elastase, cleavage was associated with destruction of Factor IX coagulant activity. In studies by others, Factors IX and IXa were inactivated by an elastase, as observed in coagulant assays with crude preparations (27). Considering related clotting factors, granulocyte elastase has been shown to rapidly inactivate the coagulant activities of preparations of Factors VII and XII but not prothrombin (28).

Because of major problems in specificity of studies involving coagulant activities, it was necessary to develop a direct assay for Factor IXa. Accordingly, Factor IX species were bound to solid-phase antibody and the activated form distinguished from the zymogen by use of a labeled inhibitor. Antithrombin III was chosen because it interacts with Factor IXa by a covalentlike bond that forms rapidly in the presence of heparin (29). The enzyme-inhibitor complex also distinguished the activated form from inactive, degraded products of Factor IX. A similar approach has been used to differentiate between inactivation and activation when Factor IX is digested with chymotrypsin and trypsin (20). It has also been used to demonstrate that a mouse monoclonal antibody that reacts to the heavy chain of Factor IXa does not inhibit either Factor XIa activation cleavages and/or subsequent binding of antithrombin III-heparin (21). By detecting generated active sites of Factor IX, the direct assay eliminates the possibility of interference due to effects on Factor VIII as would occur in coagulation or coupled Factor $\mathrm{X}$ activation assays.

Elastase can degrade antithrombin III (30), and this effect appears to be operative in the new Factor IXa assay. Therefore, the elastase-specific chloromethyl ketone or $\alpha_{1}$-antitrypsin were used to control for this effect. Even with such control and throughout the time course experiments, elastase-degraded Factor IX was unable to bind antithrombin III. In separate experiments, the procoagulant activity of the Factor IX zymogen was rapidly destroyed. This occurred despite the rapid digestion of Factor IX to form heavy and light chain-sized fragments and only a slower digestion to lower molecular weight fragments (providing calcium was present). Since similarly sized peptide fragments result from elastase and Factor XIa digestions, it appears that elastase hydrolyzes peptide bonds near, but not at, the specific $\operatorname{Arg}_{145}-\mathrm{Ala}_{146}$ and $\mathrm{Arg}_{180}-\mathrm{Val}_{181}$ bonds known to be necessary for activation of Factor IX (31). Indeed, similar to the case with thrombin (32), it is probable that the free amino group of $\mathrm{Val}_{181}$, at the amino terminus of the Factor IXa's heavy chain, is necessary for ion pair formation with $\mathrm{Asp}_{365}$ to create a functional active site. 
The interaction of elastase with Factor IXa produced the same, relatively slower, digestion to lower molecular weight fragments as with the zymogen (see Table II). On the other hand, Factor IXa was only partially inactivated by elastase as indicated by both ${ }^{125}$ I-antithrombin III-heparin binding and coagulant activity in a nonactivated assay with Factor IX-deficient plasma. The difference of the current results with Factor IXa and those previously reported using crude preparations (27) are best explained by other effects of elastase on the coagulation system. Indeed, when elastase was not inhibited following even brief incubations with Factor IXa, no binding of ${ }^{125} \mathrm{I}$-antithrombin III was detected. As mentioned previously, this was apparently because of degradative effects of the elastase on antithrombin III. Thus, it appears that Factor IXa is more resistant to inactivation cleavages than is the zymogen. In this regard, studies in which elastase-degraded Factor IX were incubated with Factor XIa are of interest. Although screening for generation of coagulant activity was negative, some ${ }^{125}$ I-antithrombin binding was observed after short incubations. This presumably relates to the degree of preservation of an active site capable of interacting with either lower molecular weight substrates or less specific inhibitors (including antithrombin III) but sufficient cleavage to destroy secondary binding sites that are needed for physiologic, macromolecular substrates. An analogous situation would be lack of fibrinogen clotting by $\gamma$-thrombin despite retention of the ability to bind antithrombin III (33).

The assay using antithrombin III binding to distinguish an active coagulation factor from its zymogen is readily applicable to other coagulation proteins. A similar approach has recently been reported for Factor $X$ (34). Adaptations of these types of assays to more complex conditions, for example, to detect Factor IX activation in plasma, whole blood, or even in vivo, should provide insights into the early steps of coagulation in normal and abnormal hemostasis.

\section{ACKNOWLEDGMENTS}

We thank Dr. Daniel Wright, Walter Reed Army Medical Center, for providing granule fractions that were used in preliminary studies. Drs. Powers, Kurachi, and Kisiel are also greatly appreciated for their generous gifts of their preparations.

This work was supported in part by grants from the $\mathrm{Na}$ tional Institutes of Health (NHLBI-17265) and from the American Heart Association of Washington (82-WA526).

\section{REFERENCES}

1. DiScipio, R. G., K. Kurachi, and E. W. Davie. 1978. Activation of human Factor IX (Christmas factor). J. Clin. Invest. 61:1528-1538.

2. Osterud, B., and S. I. Rapaport. 1977. Activation of fac- tor IX by the reaction product of tissue factor and factor VII. Additional pathway for initiating blood coagulation. Proc. Natl. Acad. Sci. USA. 74:5260-5264.

3. Kingdon, H. S., J. C. Herion, and P. G. Rausch. 1978. Cellular activation of Factor IX (Christmas factor). Thromb. Res. 13:501-507.

4. Brower, M. S., and P. C. Harpel. 1983. Alpha-1-antitrypsin-human leukocyte elastase complexes in blood: quantification by an enzyme linked differential antibody immunosorbent assay in comparison with alpha-2-plasmin inhibitor-plasmin complexes. Blood. 61:842-849.

5. Plow, E. F. 1982. Leukocyte elastase release during blood coagulation. A potential mechanism for activation of the alternative fibrinolytic pathway. J. Clin. Invest. 69:564-572.

6. Thompson, A. R. 1977. Factor IX antigen by radioimmunoassay. Abnormal Factor IX protein in patients on warfarin therapy and with hemophilia B. J. Clin. Invest. 59:900-910.

7. Powers, J. C., B. F. Gupton, A. D. Harley, N. Nishino, and R. J. Whitley. 1977. Specificity of porcine pancreatic elastase, human leukocyte elastase and cathepsin G. Inhibition with peptide chloromethyl ketones. Biochim. Biophys. Acta 485:156-166.

8. Kurachi, K., and E. W. Davie. 1977. Activation of human factor XI (plasma thromboplastin antecedent) by factor $\mathrm{XII}_{\mathrm{a}}$ (activated Hageman factor). Biochemistry. 16:58315839 .

9. Mahoney, W. C., K. Kurachi, and M. A. Hermodson. 1980. Formation and dissociation of the covalent complexes between trypsin and two homologous inhibitors, $\alpha_{1}$-antitrypsin and antithrombin III. Eur. J. Biochem. 105:545-552.

10. Theodorsson, B., U. Hedner, I. M. Nilsson, and W. Kisiel. 1983. A technique for specific removal of factor IX alloantibodies from human plasma: partial characterization of the allo-antibodies. Blood. 61:973-981.

11. West, B. C., A. S. Rosenthal, N. A. Gelb, and H. R. Kimball. 1974. Separation and characterization of human neutrophil granules. Am. J. Pathol. 77:41-66.

12. Baugh, R. J., and J. Travis. 1976. Human leukocyte granule elastase: rapid isolation and characterization. Biochemistry. 15:836-841.

13. Reisfeld, R. A., U. J. Lewis, and D. E. Williams. 1962 Disk electrophoresis of basic proteins and peptides on polyacrylamide gels. Nature (Lond.). 195:281-283.

14. Fairbanks, G., T. L. Steck, and D. F. H. Wallach. 1971. Electrophoretic analysis of the major polypeptides of the human erythrocyte membrane. Biochemistry. 10:26062617.

15. Weber, K., and M. Osborn. 1969. The reliability of molecular weight determinations by dodecyl sulfate-polyacrylamide gel electrophoresis. J. Biol. Chem. 244:44064412.

16. Visser, L., and E. R. Blout. 1972. The use of $p$-nitrophenyl $N$-tert-butyloxycarbonyl-L-alaninate as substrate for elastase. Biochim. Biophys. Acta.268:257-260.

17. Hummel, B. C. W. 1959. A modified spectrophotometric determination of chymotrypsin, trypsin, and thrombin. Can. J. Biochem. 37:1393-1399.

18. Silverstein, R. M. 1974. The assay of the bromelains using $N$ alpha-CBZ-L-lysine $p$-nitrophenyl ester and $N$ CBZ-glycine $p$-nitrophenyl ester as substrates. Anal. Biochem. 62:478-484.

19. DiScipio, R. G., M. A. Hermodson, S. G. Yates, and E. W. Davie. 1977. A comparison of human prothrom- 
bin, factor IX (Christmas factor), factor X (Stuart factor), and protein S. Biochemistry. 16:698-706.

20. Enfield, D. L., and A. R. Thompson. 1982. Factor IX activation. Cleavage of IX and detection of factor IXa by a novel, active site directed, immunospecific assay. Circulation. 66:173.

21. Thompson, A. R. 1983. Monoclonal antibody to an epitope on the heavy chain of factor IX missing in three hemophilia B patients. Blood. 62: In press.

22. Amphlett, G. W., W. Kisiel, and F. J. Castellino. 1981. The interaction of $\mathrm{Ca}^{2+}$ with human Factor IX. Arch. Biochem. Biophys. 208:576-585.

23. Bajaj, S. P. 1982. Cooperative $\mathrm{Ca}^{2+}$ binding to human factor IX. Effects of $\mathrm{Ca}^{2+}$ on the kinetic parameters of the activation of Factor IX by Factor XIa.J. Biol. Chem. 257:4127-4132.

24. Campbell, E. J., R. M. Senior, J. A. McDonald, and D. L. Cox. 1982. Proteolysis by neutrophils. Relative importance of cell-substrate contact and oxidative inactivation of proteinase inhibitors in vitro. J. Clin. Invest. 70:845-852

25. Osterud, B., B. N. Bouma, and J. H. Griffin. 1978. Human blood coagulation Factor IX. Purification, properties, and mechanism of activation by activated Factor XI. J. Biol. Chem. 253:5946-5951.

26. Zur, M., and Y. Nemerson. 1980. Kinetics of Factor IX activation via the extrinsic pathway. Dependence of $K_{\mathrm{m}}$ on tissue factor. J. Biol. Chem. 255:5703-5707.
27. Karpati, J., K. Varadi, and S. Elodi. 1982. Effect of granulocyte proteases on human coagulation factors IX and $\mathrm{X}$. The protective effect of calcium. Hoppe-Seyler's Z. Physiol. Chem. 363:521-525.

28. Schmidt, W., R. Egbring, and K. Havemann. 1975. Effect of elastase-like and chymotrypsin-like neutral proteases from human granulocytes on isolated clotting factors. Thromb. Res. 6:315-326.

29. Rosenberg, J. S., P. W. McKenna, and R. D. Rosenberg. 1975. Inhibition of human Factor IX $_{\mathrm{a}}$ by human antithrombin. J. Biol. Chem. 250:8883-8888.

30. Jochum, M., S. Lander, N. Heimburger, and H. Fritz. 1981. Effect of human granulocyte elastase on isolated human antithrombin III. Hoppe-Seyler's Z. Physiol. Chem. 362:103-112.

31. Kurachi, K., and E. W. Davie. 1982. Isolation and characterization of cDNA coding for human factor IX. Proc. Natl. Acad. Sci. USA. 79:6461-6464.

32. Magnusson, S., and T. Hofmann. 1970. Inactivation of bovine thrombin by nitrous acid. Can. J. Biochem. 48:432-437.

33. Chang, T.-L., R. D. Feinman, B. H. Landis, and J. W. Fenton II. 1979. Anti-thrombin reactions with $\alpha$ - and $\gamma$ thrombins. Biochemistry. 18:113-119.

34. Jesty, J., S. A. Morrison, and P. C. Harpel. 1982. Activated factor $\mathrm{X}$-antithrombin complexes: quantification by an enzyme-linked differential antibody immunosorbent assay. Blood. 60(Supp. 1):214a. (Abstr.) 